\title{
Task Complexity and Its Implication for Pedagogy
}

\author{
Mohammad Hossein Yousefi \\ Department of English, Khorasgan (Isfahan) Branch, Islamic Azad University, Isfahan, Iran \\ Email: mhh.yousefi@gmail.com \\ Ebrahim Ghorban Mohammadi \\ Department of English, Islamic Azad University, Khorramabad Branch, Lorestan, Iran \\ Email: ebrahimqm1354@yahoo.com \\ Mansour Koosha \\ Department of English, Khorasgan (Isfahan) Branch, Islamic Azad University, Isfahan, Iran \\ Email: mansourkoosha@yahoo.com
}

\begin{abstract}
The purpose of the present paper was to present the rationale for the Task-based Language teaching and discuss its significance within the SLA approaches to language teaching. First, different approaches to Task-based language teaching research and practice were discussed, then the notion of 'Task Complexity" has been touched upon and different models for estimating task difficulty or Task Complexity were mentioned. Attempt, then, was made to elaborate on the empirical studies within the Cognition Hypothesis (Robinson, 2003, 2005, 2007). Finally, the implications of Task Complexity for SLA research and pedagogy were widely discussed.
\end{abstract}

Index Terms - task-based teaching, task complexity, cognition hypothesis, second language acquisition

\section{INTRODUCTION}

In recent years there has been a considerable research interest in tasks, both as a construct and as a research instrument (Kuiken and Vedder, 2007). In task-based research four major approaches can be distinguished (Robinson 2007a): (i) a psychological, interactional approach, influenced strongly by the work of Long (1985); (ii) a sociocultural approach, represented by the work of researchers like Lantolf (2000) and Swain (1995); (iii) a structure-focused approach, where tasks are designed to elicit the use of a particular structure feature (Van Patten, 1996), and (iv) a cognitive, information-theoretic approach (Skehan 1998, 2001; Robinson 2001a, 2001b, 2003b, 2005a, 2007a) (Cited in Kuiken and Vedder 2007).

Tasks have, over the past 20 years, become well established as a unit of design in a communicative curriculum. They are designed to engage learners in realistic communication on the grounds that engagement in communicating meaning is likely to lead to implicit learning (Crabbe, 2007). Research on task design attempts to find variables in task design that will lead to recognized second language acquisition processes such as negotiation or noticing (Bygate et al., 2001; Ellis, 2003). Tasks, and more specifically their components, characteristics, different types, and implementation conditions, have been the focus of much recent research (Albert and Kormos, 2004).

The great advantage of tasks is that they allow for learner engagement in realizing the communicative potential of the encoded semantic resource (Widdowson, 2003) and the most important role for a language task is to confront learners with certain language problems in completing the task (Long, 1985).

Nunan (2003) pointed out that task-based language teaching is an approach to the design of language courses in which the point of departure is not an ordered list of linguistic items, but a collection of tasks. It draws on and reflects the experiential and humanistic traditions as well as reflects the changing conceptions of language itself.

Among three aspects of task-based pedagogy, to Robinson (2001a), task complexity is the task dependent and proactively manipulable cognitive demand of tasks. Different criteria for task complexity, Robinson (2001a) believes, provide a basis for decisions about sequencing tasks in a task-based syllabus as well as a framework for studying the effects of increasing L2 task complexity on production, comprehension and learning.

Despite the increasing number of different models for determining task complexity (Anderson \& Lynch, 1988; Brindley, 1987; Brown \& Yule, 1983; Candlin, 1987; Long, 1985; Prabhu, 1987; Rahimpour, 1997, 1999), Robinson's model (2001b, 2007a), seems to the present researchers that, meets the requirements of what Robinson (2001b) calls 'theoretically motivated, empirically substantiable, and pedagogically feasible sequencing criteria to syllabus design'. Robinson (2001a) also believes that this framework is a more operatioalizable framework for studying task complexity and for the design of language learning materials and task-based syllabuses since it draws on some previous SLA research as well as on some current work in applied cognitive psychology (Robinson, 2001a). He, further, relates this 
framework to issues in the study of memory, attention, and processes implicated in 'focus on form' during task performance.

It should be noted that there is no consensus over any established criteria for sequencing and grading tasks. According to Robinson's model (2001b, 2007a), which seems to us more comprehensive, tasks with many similar elements, in There-and-Then condition, and with higher reasoning demands are more cognitively complex, compared to tasks with few easily distinguished elements, in Here-and-Now condition, and with no or less reasoning demands. His resource-dispersing facet of task complexity, also, predicts that giving learners no planning time, doing two tasks simultaneously, and having no or little prior knowledge about the task in question contribute to the cognitive complexity of tasks. Many studies have, empirically, lent support to these predictions of the Cognition Hypothesis (Lee, 2007; Michel et al., 2007; Rahimpour, 1997, 1999; Gilabert, 2005, 2007; Robinson, 1995a, 2001b, 2003b, 2005a, 2007a).

\section{SignifiCANCE OF THE STUdies ON TASK COMPLEXITY}

The ordering of different tasks has prime importance in task-based instruction, as authors working within this framework argue that language learning and teaching should be sequenced by means of tasks; therefore, tasks form the basis of the curriculum (Albert and Kormos, 2004). No doubt, information about the cognitive complexity of tasks will be of prime importance to syllabus designers and language teachers adhering to TBLT (Gilabert, 2005, 2007; Rahimpour, 1997, 1999; Robinson, 2001b, 2007a). Seen from the same angle, Robinson (2001a) relates task complexity, cognitive defined, to options in syllabus design and to other issues in the implementation and assessment of task-based instruction.

The Cognition Hypothesis (Robinson, 2001a, 2001b, 2005a) claims that tasks should be designed and sequenced for the learners on the basis of increase in their cognitive complexity. And these designs and sequencing decisions should be the basis of the task-based syllabus (Long 2007; Long and Crookes 1992; Robinson 2007a; Van den Branden 2006). Moreover, Skehan and Foster (2001) believe that issues of cognitive complexity have important implications for our understanding of how attention is deployed during task completion.

One of the reasons behind this research is the need to bring together the explanations of L2 production, views of pushed output, noticing and learner uptake together and integrate them into an account of how task complexity affects performance.

\section{RATIONALE FOR TASK-BASED LANGUAGE TEACHING}

Task-based language teaching focuses on the ability to perform a task or activity without explicit teaching of grammatical structure (Rahimpour, 2008, p.50). Such an approach, it is argued that, creates more favorable conditions for the development of second language ability than does an approach that focuses on the explicit teaching and learning of the rules of the language alone (Long, 1985; Prabhu, 1987; Rahimpour, 1997, 1999; Robinson, 1995a, 2001b).

Recently, there has been a growing interest in task-based language teaching (see Bygate 1999; Bygate et al., 2001; Crabbe, 2007; Long, 2007; Skehan, 1998a; Van den Branden, 2006; Willis and Willis, 2001). This is because 'task' is viewed as central to both syllabus planning and methodology (Willis and Willis, 2001); a valid 'unit of analysis' in syllabus designs (Candlin, 1987; Long, 1985, 1996, 2007; Prabhu, 1987; Robinson, 2005a, 2007c), and it facilitates 'noticing' of L2 linguistic forms (Schmidt, 1990, 2001). Moreover, underlying each task is a series of learning opportunities (Crabbe, 2007), and it is a device which can lead to implicit learning (Ellis, 2003).

The rationale for task-based teaching (TBT) comes from different camps; Ellis (2003) provided psycholinguistic rationale, whereas, Skehan (1998a, 1998b, 2002, 2003a, 2003b) took a more cognitive approach to advocate it (see Ellis, 2000). In Widdowson's terms (2003), Skehan provided the most comprehensively theoretical rationale for task-based learning. Skehan (1998a, p.95) pointed out that "as an approach to instruction, TBT is theoretically defensible and practically feasible. The assumption here, then, is the fact that transacting tasks will engage naturalistic acquisitional mechanisms, cause the underlying interlanguage system to be stretched, and drive development forward".

Elsewhere, Skehan (2002, p.293) suggested that a task-based approach is generally based on language use, that the language learning problem is how learners, from such use, develop a system of rules, and that individualization is an important aspect of the learning situation.

From different perspective, Ellis (2003) listed three arguments in favor of task-based syllabi. According to him, "the rationale for task-based syllabuses that has been advocated by SLA researchers draws on a variety of arguments. First, it is based on the theoretical view that instruction needs to be compatible with the cognitive processes involved in L2 acquisition. Second, the importance of learner 'engagement' is emphasized. And third, tasks serve as a suitable unit for specifying learners' needs and thus for designing specific purpose courses".

In line with the cognitive approaches to language learning, Robinson (2003b) forcefully argues that task-based pedagogy facilitate the cognitive processes involved in second language production (performance) and acquisition (development), and their relationship (p.46). Similarly, Prabhu (1987) views language development as the outcome of natural processes and argues against focus on language form as inhibiting language learning. 
As proponents of Focus on Forms, Long and Crookes (1992, p.43) pointed out that "tasks provide a vehicle for the presentation of appropriate target language samples to learners - input which they will inevitably reshape via application of general cognitive processing capacities and for the delivery of comprehension and production opportunities of negotiable difficulty". Furthermore, according to a more SLA perspective to advocacy of TBT, issues such as learnability, the order of acquisition of particular L2 structures, and the implications of the input, interaction and output hypothesis are central issues (Lynch \& MacLean, 2000).

Skehan (2002), moreover, advocates TBT by stating that task-oriented approach stems from three main sources: First, evidence from more naturalistic studies suggests that learners in such situations do not follow the sequences that are typically expected in classrooms, and in language teaching materials. Second, SLA strongly suggests that language development involves the growth of an interlanguage, a rule-based system which reflects the learner's appreciation of the patterns of the target language which must be learned. And third, there is a need to build in opportunities for individualization of instruction, so that learners who are at different stages can profit in relation to the point which they have reached.

More importantly, one of the main advantages of task-based instruction is that well-designed tasks can facilitate noticing of L2 syntax, vocabulary, and phonology that may lack perceptual and psychological saliency in untutored conversational settings and so may go unnoticed and unlearned (Schmidt, 1990).

The best documented application of a task-based approach is probably Prabhu's procedural syllabus (Willis \& Willis, 2001). The Bangalore project, the communicative teaching project, took place from 1979 to 1984 and was based mainly on the premise that language form can be learnt in the classroom solely through a focus on meaning, and that grammar construction by the learner is an unconscious process (Prabhu, 1987).

\section{TASK COMPLEXITY}

Robinson (2001b) argues that task complexity is the result of the attentional, memory, reasoning, and other information processing demands imposed by the structure of the task to the language learner. Robinson (2007, p.210) regards task complexity as differences in intrinsic cognitive processing demands of tasks which will explain withinlearner variation in successfully completing any two tasks (such as doing simple addition versus calculus, or doing the simple versus complex intentional reasoning task). Ellis (2003, p.351) believes that task complexity is the extent to which a particular task is inherently easy or difficult. Different dimensions of task complexity are code complexity, cognitive complexity, and context dependency.

\section{A. Research into Task Complexity}

Robinson (1995a) lists three theoretical frameworks for task complexity. According to him, the theoretical framework for the proposed task complexity is based on research into first language acquisition (e.g., Brown \& Bellugi, 1964), research findings from second language development (Meisel, 1987), and functional linguistic theory (Givon, 1989).

It is a widely accepted idea that research into complexity of second language tasks is necessary to pedagogical decisions regarding the grading and sequencing of tasks for the purposes of syllabus design (Gilabert, 2005, 2007; Long 2007; Rahimpour 1997, 1999, 2008; Robinson, 1995a, 2001b, 2003b, 2005a, 2007a, 2007a; Robinson and Gilabert 2007; Van Den Branden 2006). Skehan (1998a, 1998b) reiterates that knowledge of task difficulty provides the teacher or syllabus designer with information about the level of challenge that a task is likely to contain, a level which the teacher will then have to match his or her knowledge with that of the students who will do the task. Skehan (1998), also, provides rationale for estimating task difficulty: "the rationale for estimating task difficulty is twofold, firstly, tasks of appropriate difficulty are likely to be more motivating for learners as they feel that they are required to meet reasonable challenges, and secondly, considering that attentional capacities are limited, tasks of appropriate difficulty mean that learners will be able to overcome the difficulties put upon their attentional resources".

In par with the above arguments, Skehan (1998b, p.134) argues that: "If the appropriate level of task difficulty is chosen, there is much greater likelihood that noticing will occur, that balanced language performance will result, and that spare attentional capacity can be channeled effectively".

Researching in the framework of the Cognition Hypothesis, Rahimpour (1997) is of the belief that criteria for distinguishing the difficulty of second language tasks are an important issue for SLA researchers, syllabus designers, and second language instructors who are concerned with implementing task-based proposals for syllabus design.

Like other researchers working in the cognitive framework (Rahimpour, 1997; Skehan, 1998a; Robinson, 2007c), Gilabert (2005) relates the construct of task complexity to the syllabus design by stating that, "the concept of task complexity was born from the need to establish criteria for sequencing tasks in a syllabus from easy/simple to difficult/complex in a reasoned way that will foster interlanguage development."

Apart from application in syllabus design, Robinson (1995a) rightly points out that the emergent debate about task complexity promises to be an important site for the development of comprehensive theories of second language acquisition. Additionally, Robinson and Gilabert (2007) argue that research into the effects of task complexity aims both at pedagogic applications of findings regarding the effects of task design and sequencing decisions on learning and performance, and also at the deeper understanding of the second language processing and learning mechanisms that 
cause these effects. To sum up, all the above statements by the authoritative figures in SLA highlight the significance of task complexity in implementing task-based pedagogy.

It is widely accepted that information about manipulating the complexity of tasks can be used to guide decisionmaking about sequencing in task-based approaches to syllabus construction (Rahimpour, 1997, 1999; Robinson, 2001b, 2003b, 2005a). Robinson (2001b) and Gilabert (2005) have, also, made a case for basing sequencing decisions in taskbased approaches to syllabus design on distinctions between the cognitive demands of tasks which contribute to their relative complexity. Having demonstrated that the complexity of tasks exert a considerable influence on learner production, Robinson (2001b) argued that sequencing tasks on the basis of their cognitive complexity is to be preferred over sequencing decisions based on task difficulty or task conditions.

Robinson (2001b, 2005a, 2007), also, holds the view that factors affecting perception of difficulty (such as anxiety) are difficult or impossible to diagnose in advance of pedagogy task performance, and are problematic as a basis for a priori prospective decisions about sequencing tasks. However, task difficulty factors are important to assess on line, and modifications to decisions regarding syllabus. Robinson also suggests that decisions about task conditions will largely be motivated by the needs analysis; so task difficulty factors play little role in sequencing decisions.

As pointed out by Gilabert (2005), task complexity is the result of the preoccupation with grading and sequencing tasks in a principled way in a task-based syllabus. Thus, information about the effects of task complexity on language production and interlanguage development are important because they help syllabus designers to design tasks from simple to complex, in a way that they gradually approximate real world tasks. More importantly, Robinson (2001b) argues that cognitive complexity is a robust and manipulable influence on learner production, and is therefore a feasible basis for design and sequencing decisions which operationalize a task-based syllabus.

Of three sets of factors discussed in task-based teaching (task complexity, task conditions, and task difficulty), Robinson (2003b) reiterates the fact that complexity differentials should be the sole basis for proactive pedagogic task sequencing in task-based approaches to syllabus design. However, Candlin (1987) and Nunan (1989) have based arguments for difficulty variables, such as motivation to perform, and anxiety about performing tasks, in sequencing and grading tasks. Still, some others, such as Prabhu (1987), have argued that task sequencing should be based on differences in task conditions (e.g., from closed, information gap, to open opinion gap tasks).

\section{B. Task Complexity and L2 Development}

Robinson's Cognition Hypothesis (2001b, 2003b, 2005a, 2007) claims that increasing the cognitive demands of tasks along certain dimensions will: (a) push learners to greater accuracy and complexity of L2 production in order to meet the greater functional and conceptual communicative demands they place on the learner; (b) promote interaction, and heightened attention to and memory for input, so increasing learning from the input; (c) cause longer term retention of input; and that (d) lead to automaticity and efficient scheduling of the components of complex L2 task performance.

More importantly, the Cognition Hypothesis predicts that along resource-directing dimensions more interactive complex tasks will result in greater amounts of interaction, and negotiation for meaning. Following Long (1996), the Cognition Hypothesis claims that such negotiation provides a content for attending to problematic forms in the input and output, and additionally that on complex versions of tasks, there will be greater attention to, and uptake of forms made salient during provision of reactive Focus on Form techniques such a recasts. Alternatively, where proactive Focus on Form is provided, for example in the form of pre-modified input to the task, then it similarly claims there will be greater use of this on complex, versus simpler task versions (Robinson and Gilabert, 2007).

\section{Different Models for Determining Task Complexity}

There have been a wide variety of models or criteria for estimating task complexity in the literature on task complexity, each highlighting one dimension of a task at hand (Anderson \& Lynch, 1988; Brindley, 1987; Brown \& Yule, 1983; Candlin, 1987; Candlin and Nunan, 1987; Long, 1985; Prabhu, 1987; Rahimpour, 1997, 1999; Robinson 2001, 2007). However, it seems to the present researchers that the latter one is more comprehensive as well as theoretically motivated and practically oriented. Because of the limitation of scope, some of these models briefly will be discussed but the Robinson's model (2001b) will be given the focal attention with respect to the research done in the field.

Brindley (1987) suggested that the following factors will determine the complexity of what the learner has to do:

1-Relevance:

Is the task meaningful and relevant to the learner?

2- Complexity:

How many steps are involved in the task?

How complex are the instruction?

What cognitive demands does the task make on the learner?

3-Amount of context provided prior to the task:

How much prior knowledge of the world, the situation or the cultural context is assumed in the way the task is framed?

4- Processability of the language of the task:

Is the language that learners are expected to produce in line with their processing ability? 


\section{5- Amount of help available to the learner:}

How much assistance can the learner get from the teacher, other learners, books or other learning aids?

6- Degree of grammatical accuracy/contextual appropriacy:

How 'standard' does the task require learners to be? And,

7- Time available to the learner;

How long does the learner have to carry out the task?

Brown and Yule (1983) have devoted a noticeable attention to task difficulty. They suggested that listening tasks can be graded with reference to speaker, intended listener, content, and support. When listening to a tape, the fewer the speakers, the easier the text will be to process. Following one speaker will be easier than following two, and so on. With respect to the intended listener, they propose that texts, especially 'authentic' texts which are not addressed to the listener, may be difficult to process. As far as 'content' is considered, they suggest that specialized vocabulary which is unfamiliar can be a source of difficulty. And finally, by 'support' they mean the provision of visual cues to a listener that facilitates the cognitive load of the listening task.

Prabhu (1987) provides the following factors for determining difficulty:

1. Information provided: the amount and type of information handled will affect difficulty.

2. Reasoning needed: the number of steps or cognitive operations (e.g. deduction, inference, or calculation) will affect difficulty.

3. Precision needed: difficulty increases with the degree of precision called for.

4. Familiarity with constraints: learners' knowledge of the world and familiarity with purposes and constraints will affect difficulty.

5. Degree of abstractness: working with concepts is more difficult than working with the names of objects or actions.

Anderson and Lynch (1988) identify a range of factors which influence difficulty;

1. the sequence in which information is presented;

2. the familiarity of the listener with the topic;

3. the explicitness of the information contained in the text;

4. the type of input;

5. the type and scope of the task to be carried out; and,

6. the amount of support provided to the listener.

Rahimpour $(1997,1999)$ proposed Task Complexity in terms of temporal reference Here-and-Now vs. There-andThen as determinants of task difficulty. He also indicated that second language narrative Here-and-Now tasks, requiring tense, context supported references are simpler than those requiring references to objects and events which are isolated in time and space. Rahimpour (1997), also, argued that second language narrative tasks requiring references to the There-and-Then are more cognitively complex than tasks requiring references to the Here-and-Now. This complexity will be manifested in the narrator's oral production in terms of accuracy, linguistic complexity, and fluency (Rahimpour, 2002, p.13).

Candlin (1987) proposed a set of criteria by which tasks might be selected and graded. These are:

1- cognitive load: this concerns the general complexity of the content of the task, including the naturalness of the sequence it may be required to follow;

2- communicative stress: more stressful tasks are seen as those which involve pressure which comes from the interlocutor, either because s/he is a native speaker or because of superior knowledge or proficiency;

3- particularity and generalizability: this concerns the clarity of the goal of the task, as well as the norms of interpretation;

4- process continuity: this derives from the familiarity of the task as well as the learner capacity to relate the task to tasks they are familiar with; and,

5- code complexity and interpretative density: the first concerns the complexity of the linguistic code, while the latter is concerned with the complexity of the operations which need to be carried out on such a code.

Skehan (1998a, 1998b) has proposed the following criteria for determining task difficulty:

1. Code complexity

-linguistic complexity and variety

-vocabulary load and variety

-redundancy and density

2. Cognitive complexity

a. Cognitive familiarity

-familiarity of topic and its predictability

-familiarity of discourse genre

-familiarity of task

b. Cognitive processing

-information processing

-amount of 'computation'

-clarity and sufficiency of information given 
-information type

3. Communicative stress

-time limits and time pressure

-speed of presentation

-number of participants

-length of texts used

-type of response

- opportunities to control interaction.

Candlin and Nunan (1987) have also suggested that activities can be graded according to the general cognitive demands they make. Their scheme has four levels as follows:

1. Attending and recognizing; the learner's ability to notice what kind of input he or she is being confronted with.

2. Making sense; the learner's ability to make sense of the input as a particular example of language, determining, for example, what particular language it is, how it is organized, how it is classified and patterned.

3. Going beyond the information given; the learner's ability to hypothesize, infer, and make judgments, for example, about the underlying meaning of the test.

4. Transferring and generalizing; the learner's ability to extrapolate from any particular texts of same type, genre, and purpose, or transferring the information gained from and about a particular text to other texts that may be of other quiet different structure, channel and purpose.

\section{Task Complexity and the Cognition Hypothesis}

As stated earlier, in a series of arguments advanced by Robinson, he proposed the most comprehensive criteria for determining task complexity (Robinson 2001b, 2003b, 2005a, 2007a, 200c). It should be mentioned that his criteria, also called Triadic Componential Framework or the Cognition Hypothesis, is not free of critique. Kuiken and Vedder (2007) have questioned the validity of the framework as being not empirically researchable and operationally feasible. Unlike Kuiken and Vedder (2007), the present researchers assume some authority to this framework and believe that further research is needed to investigate some dimensions of the Cognition Hypothesis.

Robinson (2001b) pointed out that the development of theoretically motivated, empirically substantiable, and pedagogically feasible sequencing criteria has long been acknowledged as a major goal of research aimed at operationalizing task-based approaches to syllabus design. To this end, he proposed distinctions between cognitively defined task complexity, learner perceptions of task difficulty, and the interactive conditions under which tasks are performed. Robinson (2001b, p.29) strongly argued that Task Complexity is the result of the attentional, memory, reasoning, and other information processing demands imposed by the structure of the task on the language learner. These differences in information processing demands, resulting from design characteristics, are relatively fixed and invariant. Task complexity will aid explain within learner variance when performing any two tasks. It is also argued that the cognitively simpler tasks will involve a lower error rate, and/or be completed faster.

The criteria proposed by Robinson (2001b, 2003b, 2005a, 2007a) are divided into two categories; resource-directing dimensions and resource-dispersing dimensions. Resource-directing dimensions are those in which the demands on language use made by increases in Task Complexity, and the increased conceptual demands they implicate, can be met by specific aspects of the linguistic system. For example, tasks which differ along the Here-and-Now versus There-andThen dimension obviously require the learner to distinguish between the temporality of reference (present versus past), and to use distinct deictic expressions (this, that, here, there) to indicate immediately present, versus absent object (See Rahimpour, 1997).

It is argued that increasing complexity along these dimensions therefore has the potential to direct learners' attentional and memory resources to the way that the L2 structures and code concepts, so leading to interlanguage development (Robinson, 2003b, 2007a, 2007c; Robinson and Gilabert 2007).

In contrast, increasing task complexity along the resource-dispersing dimensions does not direct learners to any specific aspects of language code which can be used to meet the additional task demands (Robinson, 2001b, 2003b, 2005a, 2007a). Taking planning time, or relevant prior knowledge away, or increasing the number of tasks that have to be performed simultaneously, simply disperses intentional resources. Although, increased along these resourcedispersing is important, since it stimulates the processing conditions under which real time language is often used, and practice along them, Robinson (2003b) argues that, facilitates real-time access to an already established and developing repertoire of language, rather than to facilitate new form-function and conceptual mapping in the L2.

In a more recent study, (Robinson, 2007a) adds $+/$ - perspective taking and makes distinction between three kinds of reasoning: +/- spatial reasoning, +/- causal reasoning, +/- intentional reasoning (see Table .3). 
TABLE 1:

THE TRIADIC COMPONENTIAL FRAMEWORK FOR TASK CLASSIFICATION-CATEGORIES, CRITERIA, ANALYTIC PROCEDURES, AND DESIGN CHARACTERISTICS (FROM ROBINSON 2007A)

\begin{tabular}{|c|c|c|}
\hline Task complexity (cognitive factors) & Task condition (interactive factors) & Task Difficulty (learner factors) \\
\hline $\begin{array}{l}\text { (classification criteria: } \\
\text { Cognitive demands) } \\
\text { (classification procedure: } \\
\text { Information-theoretic analyses) } \\
\text { (a) Resource-directing variables making } \\
\text { cognitive/conceptual demands }\end{array}$ & $\begin{array}{l}\text { (classification criteria: } \\
\text { Interactional demands) } \\
\text { (classification procedure: } \\
\text { Behavior-descriptive analyses) } \\
\text { (a) Participation variables making } \\
\text { interactional demands }\end{array}$ & $\begin{array}{l}\text { (classification criteria: Ability } \\
\text { requirements) } \\
\text { (classification procedure: Ability } \\
\text { assessment analyses) } \\
\text { (a) Ability variables and task-relevant } \\
\text { resource differentials }\end{array}$ \\
\hline $\begin{array}{l}\text { +/- here and now } \\
\text { +/- few elements } \\
\text { +/- spatial reasoning } \\
\text { +/- causal reasoning } \\
\text { +/- intentional reasoning } \\
\text { +/- perspective-taking }\end{array}$ & $\begin{array}{l}\text { +/- open solution } \\
\text { +/- one-way flow } \\
\text { +/- convergent solution } \\
\text { +/- few participations } \\
\text { +/- few contributions needed } \\
\text { +/- negotiation not needed }\end{array}$ & $\begin{array}{l}\text { h/l working memory } \\
\text { h/l reasoning } \\
\text { h/l task-switching } \\
\text { h/l aptitude } \\
\text { h/l field independence } \\
\text { h/l mind/intention-reading }\end{array}$ \\
\hline $\begin{array}{l}\text { (b) Resource-dispersing } \\
\text { Variables making } \\
\text { performative/procedural demands }\end{array}$ & $\begin{array}{l}\text { (b) Participant variables } \\
\text { making interactant demands }\end{array}$ & $\begin{array}{l}\text { (b) Affective variables and state-trait } \\
\text { differentials }\end{array}$ \\
\hline $\begin{array}{l}\text { +/- planning time } \\
+/ \text { - single task } \\
+/ \text { - few steps } \\
\text { +/- independency of steps } \\
\text { +/- prior knowledge }\end{array}$ & $\begin{array}{l}\text { +/- same proficiency } \\
\text { +/- same gender } \\
\text { +/- familiar } \\
\text { +/- shared content knowledge } \\
\text { +/- equal status and order } \\
\text { +/- shared cultural knowledge }\end{array}$ & $\begin{array}{l}\text { h/l openness to experience } \\
\text { h/l control of emotion } \\
\text { h/l task motivation } \\
\text { h/l processing anxiety } \\
\text { h/l willingness to communicate } \\
\text { h/l self-efficacy }\end{array}$ \\
\hline
\end{tabular}

\section{Discussion AND CONCLUSIONS}

As discussed earlier in this paper, the ordering of different tasks has prime significance in task-based teaching, as scholars working within this framework argue that language learning and teaching should be sequenced by means of tasks; therefore, tasks form the basis of the curriculum (e.g. Albert and Kormos, 2004). No doubt, information about the cognitive complexity of tasks will be of prime importance to syllabus designers and language teachers adhering to TBLT (Gilabert, 2005, 2007; Robinson, 2001b, 2007a). Seen from the same angle, Robinson (2001a) relates task complexity, cognitively defined, to options in syllabus design and to other issues in the implementation and assessment of task-based instruction.

It was argued, based on the Cognition Hypothesis (Robinson, 2001a, 2001b, 2005a), that tasks should be designed and sequenced for the learners on the basis of the increase in their cognitive complexity. And these designs and sequencing decisions should be the basis of the task-based syllabus (Long 2007; Long and Crookes 1992). Language teachers and syllabus designer should assume central role for the Task Complexity while designing pedagogical tasks for students. This, in turn, is in favor of finding other criteria along with linguistic factors in syllabus design.

\section{Pedagogical Implications}

The present study has a number of pedagogical implications for SLA researchers, syllabus designers, and language testing specialists. Firstly, it was demonstrated that task complexity leads to more learner uptake and consequently more opportunities for Focus-on-Form, for pushed output, and 'noticing', and language acquisition opportunities. Secondly, this study claimed that task-based teaching demands proficient language teachers that should react promptly to the learners' non-target like utterances. Thirdly, the implications of this study for syllabus designers is that cognitive complexity is a more robust and valid criterion for selecting and grading of pedagogical tasks. That is to say, task complexity can be manipulated for the purpose of matching with learners' developmental sequences and their proficiency levels. Furthermore, task complexity can be manipulated in order to optimize opportunities for 'noticing' and for interlanguage development.

As pointed out by Gilabert (2005), the manipulation of task complexity can be combined with an array of pedagogical forms of intervention such as input flooding, recasts or elicitations to achieve higher levels of accuracy. Likewise, Robinson (2001a, 2001b) argues that if increasing complexity along resource-directing variables has the potential to draw learners' attention to the forms in their own production, it can also lead them to focus on the input they receive. Therefore, by careful analysis of task difficulty and integrating the findings in sequencing tasks, syllabus designers as well as instructors can make sure they have provided appropriate material and instruction for enhancing 
learners' attention to input and output structures. This learners' attention to linguistic features can lead to a better grasp of the L2 students are attempting to learn.

\section{REFERENCES}

[1] Albert, A. and Kormos, J. (2004).Creativity and narrative task performance; an explanatory study. Language Learning, 54:2, 227-310.

[2] Anderson, A. \& Lynch, T. (1988). Listening. Oxford: Oxford University Press.

[3] Brindley, J. (1987). Factors affecting task difficulty. In D. Nunan, (Ed.), Guidelines for the development of curriculum resource (pp.45-56). Adelaide: National Curriculum Resource Center.

[4] Brown, R., \& Bellugi, U. (1964). 'Three processes in the child's acquisition of syntax'. Harvard Educational Review. 34: 133151.

[5] Brown, G. \& Yule, G. (1983).Teaching the spoken language. Cambridge: Cambridge University Press.

[6] Bygate, M. (1999).Task as context for framing, reframing, and unframing of language. System, 27, 33-48.

[7] Bygate, M., Skehan, P. \& Swain, M. (2001). Introduction' In M. Bygate, P. Skehan and M. Swain (Eds.).Researching pedagogic tasks, second language learning, teaching and testing. Harlow: Longman.

[8] Candlin, C. (1987). Towards task-based language learning. In Candlin, C. \& Murphy, D. (Eds.), Language learning tasks (pp.5-22). Englewood Cliffs, NJ: Prentice Hall.

[9] Crabbe, D. (2007). Learning opportunities: adding learning value to tasks. ELT Journal, 61/2.117-125.

[10] Ellis, R. (2003). Task-based language learning and teaching. Oxford: Oxford University Press.

[11] Gilabert, R. (2005). Task complexity and L2 narrative oral production. Unpublished Ph. D. Dissertation. University of Barcelona, Spain.

[12] Gilabert, R. (2007). Effects of manipulating task complexity on self-repair during L2 oral production. IRAL (45), 215-240.

[13] Givon, T. (1989).Mind, code, and context. essays in pragmatics. Hillsdale, NJ:Erlbaum.

[14] Kumaravadivelu, B. (2006). TESOL methods: changing tracks, challenging trends, TESOL Quarterly, 40(1), 59-81.

[15] Lantolf, J (Ed.). (2000). Sociocultural theory and second language learning. Oxford: Oxford University Press.

[16] Lee, S. (2007). Effects of textual enhancement and topic familiarity on Korean EFL students' reading comprehension and learning of passive form. Language Learning. 57:1, 87-118.

[17] Long, M. H. (1985). A role for instruction in second language acquisition: task-based language teaching. In K. Hyltenstam and M. Pienemann (Eds.), Modeling and assessing second language acquisition (pp.77-99).Clevedon: Multilingual Matters.

[18] Long, M. H. (1996). The role of linguistic environment in second language acquisition. In W.C. Ritchie \& T. K. Bhatia Eds.).Handbook of second language acquisition.(pp.413-463). San Diego; Academic Press.

[19] Long, M. (Ed.) (2007). Problems in SLA, Mahwah, NJ: Erlbaum.

[20] Long, M. H. \& Crookes, G. (1992). Three approaches to task-based syllabus design, TESOL Quarterly, 26(1), 27-56.

[21] Lynch, T., \& MacLean, J. (2000). Exploring the benefits of task repetition and recycling for classroom language learning, Language Teaching Research, 4, 221-250.

[22] Meisel, J. (1987). Reference to past events and actions in the development of natural language acquisition. In C. Pfaff (Ed.), First and second language acquisition processes (pp.206-224). Cambridge, MA: Newbury House.

[23] Michel, M. Kuiken, F., \&Vedder, I. (2007).The influence of complexity inmonologic versus dialogic tasks in Dutch L2. IRAL, 45, 241-259.

[24] Nunan, D. (1989). Designing tasks for the communicative classroom. Cambridge: Cambridge University press.

[25] Nunan, D. (2003). Second language teaching and learning. Boston, U.S.A: Newbery house.

[26] Prabhu, N. S. (1987).Second language pedagogy. Oxford: Oxford university press.

[27] Rahimpour, M. (1997).Task complexity, task condition and variation in L2 oral discourse. Unpublished PhD Thesis. The University of Queensland, Brisbane, Australia.

[28] Rahimpour, M. (1999).Task complexity and variation in interlanguage. In N. Jungheim\& P. Robinson (Eds.), Pragmatics and Pedagogy: Proceedings of the $3^{\text {rd }}$ Pacific Second Language Research Forum, 2, 115-134, Tokyo: PacSLRF.

[29] Richards, J. C. \& Rodgers, T. S. (2001). Approaches and methods in language teaching. Cambridge: Cambridge University Press.

[30] Robinson, P. (1995a). Task complexity and second language narrative discourse, Language Learning, 45(1), 99-140.

[31] Robinson, P. (1995b). Attention, memory and the "noticing" hypothesis. Language Learning. 45: 283-331.

[32] Robinson, P. (1996). Task complexity and second language syllabus design: data-based studies and speculations. Working papers in language and linguistics, 1(1), 1-15.

[33] Robinson, P. (1998). State of the art: SLA theory and second language syllabus design. The Language Teacher, 22(4).7-14.

[34] Robinson, P. (2000). Task complexity and reasoning demands: effects on dyadic NNS- NNS interaction, fluency, accuracy, complexity and incorporation of input. Unpublished data, Aoyama Gakuin University, Tokyo.

[35] Robinson, P. (2001a). Task complexity, task difficulty, and task production: exploring interactions in a componential framework. Applied Linguistics, 22, 27-57.

[36] Robinson, P. (2001b). Task complexity, cognitive resources, and syllabus design: A triadic framework for examining task influences on SLA. In P. Robinson (Ed.), Cognition and second language instruction (pp.285-316). Cambridge: Cambridge University Press.

[37] Robinson, P. (2003b). The cognition hypothesis, task design, and adult task-based language learning. Second Language Studies, 21(2), 45-105.

[38] Robinson, P. (2005a). Cognitive complexity and task sequencing: A review of studies in a componential framework for second language task design. International Review of Applied Linguistics in Language Teaching. 43(1): 1-33. 
[39] Robinson, P. (2007a). Criteria for grading and sequencing pedagogic tasks. In investigating tasks in formal language learning, Maria Del Pilar Garcia Mayo (Ed.), 2-27.Clevedon: Multilingual Matters.

[40] Robinson, P. (2007c). Task complexity, theory of mind, and intentional reasoning: Effects on L2 speech production, interaction, uptake and perceptions of task difficulty. IRAL, 193-213.

[41] Robinson, P., \& Gilabert, R. (2007). Task complexity, the Cognition Hypothesis and second language learning and performance. $R A L 45,161-176$.

[42] Schmidt, R. (1990). The role of consciousness in second language learning. Applied Linguistics.11: 17-46.

[43] Schmidt, R. (2001). Attention in P. Robinson (Ed.): Cognition and second language instruction. (PP. 3-32). Cambridge: Cambridge University Press.

[44] Skehan, P. (1996). A framework for the implementation of task-based instruction. Applied Linguistics, 17(1), 38-62.

[45] Skehan, P. (1998a). Task-based instruction. Annual Review of Applied Linguistics, 18, 268-286.

[46] Skehan, P. (1998b). A cognitive approach to language learning. Oxford: Oxford University Press.

[47] Skehan, P. (2002). A non-marginal role for task.ELT Journal. 56/3, 289-295.

[48] Skehan, P. (2003a). Focus on form, tasks, and technology. Computer Assisted Language Learning, 16/5, pp. $391-411$.

[49] Skehan, P. (2003b). Task-based instruction, Language Teaching, 36, 1-14.

[50] Skehan, P., \& Foster, P. (1997). Task type and task processing conditions as influences on foreign language performance. Language Teaching Research, 1(3), 1-27.

[51] Skehan, P., \& Foster, P. (2001).Cognition and tasks. In' Cognition and second language instruction,' P.Robinson (Ed.), 183205. Cambridge: Cambridge University Press.

[52] Swain, M. (1995). Three functions of output in second language. In H.G. Widdowson, G. Cook \& B. Seidlhofer (Eds.), Principles and practice in applied linguistics: studies in honor of H. G. Widdowson (pp.125-144). Oxford: Oxford University Press.

[53] Urwin, J. (1999). Second language listening task complexity. Unpublished Ph.D. dissertation, Monash University, Australia.

[54] Van den Branden, K. (Ed.) (2006). Task-based language education. Cambridge: Cambridge University press.

[55] Van Patten, b. (1996).'Attending to form and content in the input'. Studies in Second Language Acquisition, 12: 287-301.

[56] Van Patten, B. (2004). Input processing in SLA. In Van Patten (Ed.), Processing instruction Theory, research, and commentary (pp.5-31). Mahwah, NJ: Lawrence Erlbaum.

[57] Widdowson, H. G. (2003). Defining issues in English language teaching. Oxford: Oxford University Press.

[58] Willis, D. \& Willis, J. (2001).Task-based language learning. In D, Nunan. \& Carter, R. (Eds.), The Cambridge guide to teaching English to the speakers of the other languages (pp.173-179). Cambridge: Cambridge University Press.

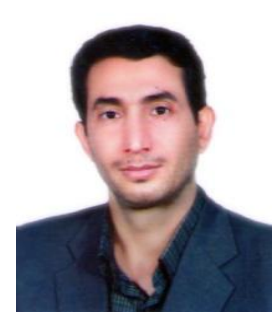

Mohammad Hossein Yousefi is currently doing his $\mathrm{PhD}$ at the Islamic Azad University of khorasgan (Isfahan), Iran. His main research interests are; Task-based Language Teaching, Cognitive Complexity, Corrective Feedback, and SLA. He, also, teaches ESP for undergraduate students at the Islamic Azad University of Bonab, Iran.

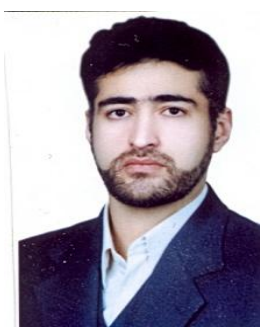

Ebrahim Ghorban Mohammadi is currently a $\mathrm{PhD}$ candidate in Teaching English as a Foreign Language in Islamic Azad University, Khorasgan (Isfahan) Branch. He has published papers in domestic and international journals. His areas of interest include pronunciation and vocabulary acquisition, EFL reading and writing, language assessment, and psycholinguistics.

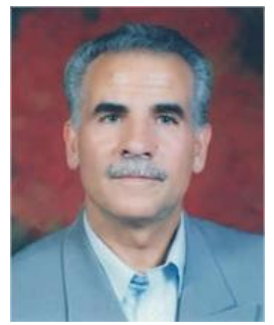

Mansoor Koosha is an associate professor of applied linguistics. He received his B.A. in English Language and Literature from Isfahan University, Iran, in 1961. He earned his M.A. in Teaching English as a Foreign Language (TEFL) from the American University of Beirut, Lebanon, in 1970. Later, he did his PhD studies in English Education in University of Colorado, U.S.A., in1980. He is currently an associate professor at Islamic Azad University, Khorasgan (Isfahan) Branch, Iran. He has published several ESP textbooks for EFL students in Iran, and has also been the author of several articles in Iran and abroad. His research interests include material development, L2 acquisition, EFL reading, translation studies, and ESP. 